\title{
Hippocrateaceae endémicas del Perú
}

\section{Blanca León ${ }^{1,2}$}

${ }^{1}$ Museo de Historia Natural, Av. Arenales 1256, Aptdo. 14-0434, Lima 14, Perú

2 Plant Resources Center, University of Texas at Austin, Austin TX 78712 EE.UU.

blanca.leon@mail.utexas.edu

\section{Resumen}

La familia Hippocrateaceae es reconocida en el Perú por presentar nueve géneros y 52 especies (Brako \& Zarucchi, 1993; Ulloa Ulloa et al., 2004), la mayoría de ellas lianas. En este trabajo reconocemos tres especies endémicas en igual número de géneros. Las Hippocrataceae endémicas ocupan la región Bosques Húmedos Amazónicos, entre los 100 y 135 m de altitud. Se aplicaron las categorías y criterios de la UICN a dos especies. Ninguna de las especies se encuentra representada en el Sistema Nacional de Áreas Naturales Protegidas por el Estado.

Palabras claves: Hippocrateaceae, Perú, endemismo, plantas endémicas.

\section{Abstract}

The Hippocrateaceae are represented in Peru by nine genera and 52 species (Brako \& Zarucchi, 1993; Ulloa Ulloa et al., 2004), mostly lianas. Here we recognize three endemic species in the same number of genera. These endemic species are found in the Humid Lowland Amazonian Forests region, between 100 and 135 m elevation. We applied IUCN categories and criteria to two species. No endemic Hippocrateaceae have been registered to date in Peru's protected areas system.

Keywords: Hippocrateaceae, Peru, endemism, endemic plants.

\section{Cheiloclinium obtusum A.C. Sm.}

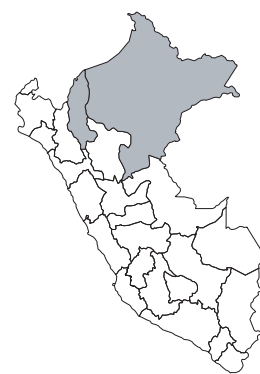

Publicación: Brittonia 3(3): 516. 1940. Colección tipo: G. Klug 381 Herbarios: NY, US.

Nombre común: Desconocido. Registro departamental: AM, LO. Regiones Ecológicas: BHA; $100 \mathrm{~m}$. SINANPE: Sin registro.

Herbarios peruanos: Ninguno.

Observaciones: Árbol conocido de poblaciones dispersas en la Amazonía peruana. El ejemplar tipo fue recolectado en 1929, de los alrededores de Iquitos. Otra población es conocida de la cuenca del Imaza. No ha sido posible evaluarlo, ni asignarle una categoría.

\section{Peritassa killipii A.C. Sm.}

\section{DD}

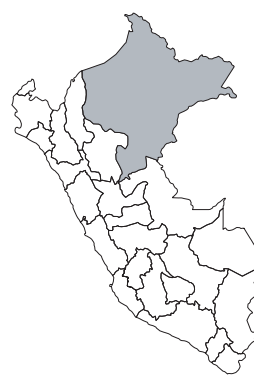

Publicación: Brittonia 3(3): 513-514. 1940.

Colección tipo: E.P. Killip \& A.C. Smith 27777

Herbarios:

Nombre común: Desconocido.

Registro departamental: LO.

Regiones Ecológicas: BHA; $135 \mathrm{~m}$.

SINANPE: Sin registro.

Herbarios peruanos: Ninguno.

Observaciones: Árbol pequeño, conocido aparentemente sólo de la colección tipo, una planta recolectada en el occidente de la Amazonía peruana, en la cuenca del Huallaga, en 1929.
3. Tontelea myrsinoides A.C. Sm.

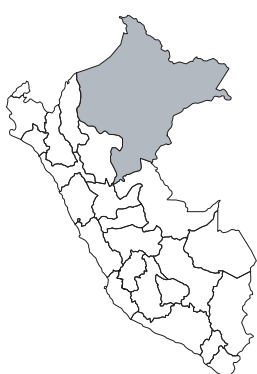

DD

Publicación: Brittonia 3(3): 499. 1940.

Colección tipo: G. Klug 712

Herbarios: NY, US.

Nombre común: Desconocido.

Registro departamental: LO.

Regiones Ecológicas: BHA; $100 \mathrm{~m}$.

SINANPE: Sin registro.

Herbarios peruanos: AMAZ (1), USM (1).

Observaciones: Liana conocida de dos localidades en los alrededores de Iquitos. El ejemplar tipo fue recolectado en 1929. 